\title{
The Sverdlovsk Region: steps towards sustainable development and energy security
}

\author{
N. Smirnov ${ }^{1} \&$ E. Menshikova ${ }^{2}$ \\ ${ }^{I}$ Ministry of Energy and Housing and Communal Sector \\ of the Sverdlovsk Region, Russia \\ ${ }^{2}$ The Urals Institute of the Russian Presidential Academy of \\ National Economy and Public Administration, Russia
}

\begin{abstract}
Rapid changes in the global market and economy offer opportunities for growth and provide a wider choice of location for international direct investment. The Sverdlovsk Region has always been a leading force in Russia's Gross Domestic Product although, in previous years, the regional economy has faced a number of challenges.

The authors provide a wide overview of the region to determine spheres for further growth and to set forward proposals to consolidate regional energy security. There are several ways of strengthening the Sverdlovsk regional energy system to provide a consistent strategy-based approach and to develop local energy resources. The results reported in this paper were based on the use of analytical modelling.

Keywords: the Sverdlovsk Region, regional energy market overview, energy security, sustainable development.
\end{abstract}

\section{Introduction}

The Sverdlovsk Region has always been a leading force in the growth of Russia's Gross Domestic Product, although, in previous years, the regional economy has faced a number of challenges. The regional industry has a constant need for affordable energy supplies to contribute to growth. Therefore, an improvement in the energy system is a subject of prime political importance.

The energy balance of the region tended to be in surplus in the past. The Sverdlovsk Region can supply more than the required generating capacities and 
has the opportunity to deliver electric power to neighboring regions. In spite of that its regional government has been confronted with a range of problems affecting the industrial sector, specifically in metallurgy. At the end of 2013 RUSAL, a global aluminum producer announced having to stop production at its Bogoslovski aluminum plant in Krasnoturinsk, the Sverdlovsk Region. The reason being that high cost of energy made production unprofitable. The drop in the price of aluminum, together with expensive electricity and heat energy resulted in a lack of competitiveness in the international market.

This situation demonstrated the presence of deep contradictions in the system, which supplied expensive energy in spite of it's over production capacity.

Energy security implies the uninterrupted supply of the requested quantity of energy at an affordable price. Any other alternatives threaten both energy and economic security. This situation highlights the necessity of analysing the whole regional energy system.

\subsection{Model of Short-Term Energy Security (MOSES) as an analysis tool}

The Model of Short-Term Energy Security (MOSES) was developed by the International Energy Agency as a tool to evaluate the state of affairs in the field. It is based on a list of indicators grouped together by energy sources: crude oil, coal, nuclear power, etc. Each group has a couple of risk and resilience indicators. This model can provide a first level analysis focused on supplies security of the region. It is significant that MOSES was developed to investigate energy security including not only internal features but also international energy inputs and outputs. That is why one can consider the Russian energy system outside this region as foreign.

The MOSES model results in groups of energy security ranked from " $\mathrm{A}$ " to "E" when "A" marks the complete independence and the best energy security. Based on that, one can have an overview of groups of risks and factors for the Sverdlovsk Region.

\section{Supply group's analysis of the Sverdlovsk Region}

\subsection{Crude oil}

The Sverdlovsk Region does not produce crude oil. This item is the only external risk linked to the net-import dependence. However, the level of political stability is high as the region is part of a united Russian energy system. Therefore the indicator of crude oil supply delivery is low-risk in spite of the absence of domestic production. The Region also has its own oil deposits in Subardinskoe and Suharechenskoe still unexploited in order to protect the zone's environment. The indicators linked with the diversity of suppliers and transport pipelines have no reason to be detailed in the model. Moreover, Sverdlovsk is a transit region for 11 pipelines going from Siberia to Central Russia. This infrastructure may be used in case of the energy system needing to be extended to provide more facilities for the new regional crude oil production plants. 
The summary of findings on crude oil security results in a " $\mathrm{D}$ " indicator that means near full dependence on outer supplies and security deficiency.

\subsection{Oil products}

The range of oil products supplies includes motor gasoline, distillates and heating oil. Gasoline and distillates are not included in fuel mix calculations and the heating oil takes up about $1 \%$ in electric power production. This sort of fuel may also be used as an emergency fuel in extremely low temperatures.

The indicators for the oil products faced the same challenges as those for crude oil. The majority of oil products are imported but the overall consumption of this type of fuel in energy systems is non-threatening. A sufficient amount of pipelines and resource storage results in a " $\mathrm{C}_{2}$ " group of energy security that means mid-range.

\subsection{Natural gas}

This fuel is overwhelmingly important for the Region. More than 50\% of energy production is provided by natural gas. Natural gas is a well-known high heat capacity fuel and a reference fuel because of a number of uses and advantages.

The internal natural gas supply market is fully monopolized by GAZPROM and there is a high level of political and economic stability in this regard. Historically the Sverdlovsk Region possesses a major pipeline transport system, i.e. the Byhara-Ural cross-country gas pipeline. Yekaterinburg is the Headquarters of GAZPROM Transgas Yekaterinbug Ltd. - the cross-region gas pipeline operator which celebrates its $50^{\text {th }}$ anniversary this year.

The send-out capacity from gas storage meets peak daily demand. Despite almost complete absence of supplier diversity, the level of cooperation in case of requiring supplement deliveries is normally high. In addition, the region relies on its own natural gas fields such as those in Byharovskoe, Kedrovskoe and Mihailovskoe. The recoverable gas is less than from Tymen gas but fuel is suitable as a component for non-hydrocarbon fuel production, for example dimethyl ether. For this reason the group level of regional energy security can be considered to be medium.

Summary of findings on natural gas security results in a "C" group classification. Taking into consideration the significance of the group rank this is very favorable.

\subsection{Coal}

Coal security analysis is similar to the natural gas and its significance is of the same importance. Coal covers more than $40 \%$ of the total fuel mix of the Sverdlovsk Region. Using coal in electric power production necessitates the construction, maintenance and decommissioning of ash-disposal areas. That's why fuel for electric power production coal comes with a high level of pollution. One of the lowest ecological compatibility generating plants of the Sverdlovsk Region - Reftinskaya Power Station - operates on coal. Along with the releases 
of carbonic oxide, nitrogen gas, sulfur products, the Refetinskaya Power Plant produces 4 billion tonnes of ash solid residues per annum. The Ministry of Energy is committed to improving the situation. Three years ago the Sverdlovsk Region Government and ENEL Wholesale Generation Company signed an Agreement for Cooperation in the matter of Environmental Protection, including middle and long term improvements in Reftinskaya's ecological index. In addition to Reftinskaya's other generation plants in the Region are based on coal.

The next challenge linked with coal is the high level of dependence on external suppliers. In this case the external vendor is a country outside the Russian Federation. The key deliverer of the coals for the Sverdlovsk Region is Ekibaztuzsky coal-mining field, located in Kazahstan, Pavlodarsk Region. This supply chain started during the USSR period and is still operative.

The coal group indicators results in an "E" classification. This energy security group carries low supplier diversity and the use of only one port in the region.

\subsection{Nuclear power}

The nuclear power analysis requires reevaluating its limitations. The highest level "A" in a summary of findings on nuclear power security concerns the national energy security rather than that of the region. These considerations explain why the advanced level of development was deemed to require 10 nuclear plants. It is obvious that unlike the rest of the country, the Sverdlovsk Region has no need to posses such a large number of nuclear power stations. Therefore, the indicator of prime interest in this group is the diversity of reactor models.

Beloyarskaya nuclear power plant is situated in Zarechny, the Sverdlovsk Region. This plant operates three power-generating units and a fourth is ready to start. This unit is going to replace the first two which are ready for decommissioning. The third power-generating unit with the fast-neutron nuclear reactor №600 is the only one in the world offering long term sustainability and safety. The new fast-neutron nuclear reactor meets all national and international requirements of atomic engineering. The site is also scheduled to be the location of a fifth power-generating unit fast-neutron nuclear reactor which will deliver the new generation in nuclear power group energy security.

Summarizing the nuclear power group indicators, the aim is to reach "A" level of security.

\subsection{Results of evaluating the short-term energy security of the Sverdlovsk Region}

This paper provides an overview of energy security supplies indicators, ranking the type of energy generation plants from "A" to "E". The Sverdlovsk Region energy systems have the higher level of fuel diversification. The average profile of the region is "C" which indicates a level of middle risk and resilience due to both external and domestic factors. 
Such analysis as with a traditional SWOT helps not only to define threats and weaknesses, but also to find out ways to transform them into strengths and opportunities.

The first priority for sustainable development and energy security is to be able to rely on local fuel resources. To this effect, there is a list of innovations to be implemented in the regional Electric-power Development Program and Scheme, also including peats, hydropower and dimethyl ether production.

\section{Conclusion}

The Sverdlovsk Region currently faces the challenges of sustainable and affordable energy production. Further economic development is not possible without a re-evaluation of the energy scenario. Any new solution to be implemented needs to refer to the important aspect of energy security. A new system could not be seen as successful without achieving balance and safety.

The Sverdlovsk Region's energy system presents a good medium level of energy security and has a number of facilities that will continue to grow in due course.

It is essential to continue to evolve systematically towards a sustainable energy system and the Regional Government is committed to that policy.

\section{References}

[1] Measuring Short-Term Energy Security (2013, November 10). International Energy Agency. Retrieved from: http://www.iea.org/publications /freepublications/publication/Moses.pdf

[2] On Approval of the Sverdlovsk Region Electric-power Development Program and Scheme, $\S 540$ (2013). 